\title{
Essential oils purified from Schisandrae semen inhibits tumor necrosis factor-a-induced matrix metalloproteinase- 9 activation and migration of human aortic smooth muscle cells
}

\author{
Jin-Woo Jeong ${ }^{1}$, Joo Wan Kim², Sae Kwang Ku³ , Sung Goo Kim², Ki Young Kim², Gi-Young Kim², Hye Jin Hwang 5,6,
} Byung Woo Kim ${ }^{5,7}$, Hae Young Chung ${ }^{8}$, Cheol Min Kim ${ }^{9}$ and Yung Hyun Choi ${ }^{1,5^{*}}$

\begin{abstract}
Background: The migration of vascular smooth muscle cells from the tunica media to the subendothelial region may be a key event in the development of atherosclerosis after arterial injury. In this study, we investigated the potential mechanisms underlying the anti-atherosclerotic effects of Schisandrae Semen essential oil (SSeo) in human aortic smooth muscle cells (HASMCs).

Methods: Metalloproteinase-2/9 (MMP-2/9) activity was evaluated by gelatin zymography and gelatinase activity assay kit. The possible mechanisms underlying SSeo-mediated reduction of by tumor necrosis factor (TNF)-a-induced cell invasion and inhibition of secreted and cytosolic MMP-9 production in HASMCs were investigated.

Results: Our results indicate that SSeo treatment has an inhibitory effect on activation as well as expression of MMP-9 induced by TNF-a in HASMCs in a dose-dependent manner without significant cytotoxicity. SSeo attenuated nuclear translocation of TNF-a-mediated nuclear factor-kappa B (NF-kB) and blocked degradation of the NF-kB inhibitor proteins as well as the production of reactive oxygen species. SSeo also reduced TNF-a-induced production of pro-inflammatory mediators such as nitric oxide and prostaglandin $E_{2}$ and inhibited inducible nitric oxide synthase and cyclooxygenase-2 expression in HASMCs. Furthermore, the Matrigel migration assay showed that SSeo effectively reduced TNF-a-induced HASMC migration compared with that in the control group.
\end{abstract}

Conclusions: Taken together, these results suggest that SSeo treatment suppresses TNF-a-induced HASMC migration by selectively inhibiting MMP-9 expression, which was associated with suppression of the NF-kB signaling pathway. Taken together, these results suggest that SSeo has putative potential anti-atherosclerotic activity.

Keywords: Schisandrae semen essential oil, HASMCs, Invasion, MMP-9, NF-KB

\section{Background}

Proliferation and migration of vascular smooth muscle cells (VSMCs) from the tunica media to the subendothelial region play a major role in the development and progression of atherosclerosis, which is a progressive pathological disorder that often leads to cardiovascular and cerebrovascular diseases. During the early stages of atherosclerosis or

\footnotetext{
*Correspondence: choiyh@deu.ac.kr

'Department of Biochemistry, Dongeui University College of Korean

Medicine, Busan 614-052, Republic of Korea

${ }^{5}$ Anti-Aging Research Center \& Blue-Bio Industry RIC, Dongeui University, Busan 614-714, Republic of Korea

Full list of author information is available at the end of the article
}

arterial wall injury, VSMCs migrate to the intimal layer of the arterial wall, causing intimal thickening [1,2]. Accumulating evidence indicates that activation of matrix metalloproteinases (MMPs) may contribute to the pathogenesis of atherosclerosis by facilitating migration of VSMCs through degradation or remodeling of the extracellular matrix (ECM) surrounding cells [3-5]. Among MMPs, gelatinase MMP-9 is particularly critical for the development of arterial lesions via its regulation of both VSMC migration and proliferation in the pathogenesis of atherosclerosis [6-8]. The cytokine tumor necrosis factor (TNF)- $\alpha$ secreted by VSMCs accumulates in atherosclerotic

\section{Ciomed Central}

(c) 2015 Jeong et al.; licensee BioMed Central. This is an Open Access article distributed under the terms of the Creative Commons Attribution License (http://creativecommons.org/licenses/by/4.0), which permits unrestricted use, distribution, and reproduction in any medium, provided the original work is properly credited. The Creative Commons Public Domain Dedication waiver (http://creativecommons.org/publicdomain/zero/1.0/) applies to the data made available in this article unless otherwise stated. 
lesions and induces marked proliferation and migration of VSMCs [8,9]. The synthesis and secretion of MMP-9, of which basal levels are usually low in VSMCs, but not MMP-2, can be stimulated by a variety of stimuli including growth factors and cytokines such as TNF- $\alpha$ through activation of a transcription factor nuclear factor-kappa $B$ (NF-кB) [10-13]. NF-кB is normally present in the cytosol in an inactive state through interaction with inhibitor of NF- $\mathrm{B}$ ( ( $\kappa \mathrm{B})$ proteins. The NF- $\mathrm{B}$ dimer dissociates from $I \kappa B$ and translocates to the nucleus following inflammatory or other stimuli that leads to degradation of the $\mathrm{I} \kappa \mathrm{B}$ protein. In the nucleus, NF- $\mathrm{kB}$ binds to promoter regions and induces the expression of a wide variety of genes including various inflammatory factors, adhesion molecules, and MMPs [14,15].

Although the relative contribution of reactive oxygen species (ROS) and inflammatory mediators in the vasculature remains ambiguous, they integrate cellular signaling pathways involved in VSMC proliferation and migration associated with atherosclerosis. Under normal physiological conditions, ROS quenching by antioxidant enzymes is sufficient to maintain the restitution of antioxidant/pro-oxidant equilibrium following an oxidative challenge [16,17]. However, when the production of ROS exceeds endogenous antioxidant capacity, oxidative stress results in abnormal physiological responses, with subsequent severe damage to proteins, lipids, and DNA. In addition, inflammatory factors also play important roles stimulating localized pathological process in atherogenesis [18-20]. Furthermore, oxidative stress can also activate or increase the expression of redox-sensitive genes, including pro-inflammatory factors and MMPs, through activation of the NF- $\mathrm{kB}$ signaling pathway [21,22].

Essential oils, which are complex mixtures of volatile compounds produced by aromatic plants, show various pharmacological effects such as antioxidant, antimicrobial and antiseptic effects [23,24]. Plant essential oils exert beneficial effects on various smooth muscle disorders [25-33]. Schisandrae fructus [Schisandra chinensis (Turcz.) Baillon] is a medicinal herb widely used to treat various inflammatory and immune diseases, central nervous and cardiovascular disorders, hypertension, and blood sugar and acid-base balance in East Asian countries such as Korea, Taiwan, Japan, China, and Russia [34,35]. According to recent research, essential oil extracted from Schisandrae fructus has been found to have pharmacological activities such as antibacterial and antioxidant activities [36-39]. However, the underlying molecular mechanisms of the potential anti-atherosclerosis effects of Schisandrae semen have not yet been elucidated, particularly with respect to the inhibitory activity of MMPs and migration in VSMCs. Therefore, in the present study, Schisandrae semen essential oil (SSeo) was examined for its potential anti-atherosclerotic effects in human aortic smooth muscle cells (HASMCs). We provide evidence showing that SSeo suppressed TNF- $\alpha$-induced MMP-9 expression by inhibiting MMP-9 gene transcription. Additionally, suppression of HASMC migration by SSeo appeared to block MMP-9 expression and intracellular ROS accumulation by inhibiting the NF- $\mathrm{kB}$ signal pathway.

\section{Methods}

\section{Preparation of SSeo}

Reddish brown clear SSeo was prepared by maceration and hydrodistillation methods as follows. Briefly, dried seeds of S. chinensis (Turcz.) Baillon were collected around Mungyeong-city (Gyeongbuk, Republic of Korea) on October 2013 and completely dried at $180^{\circ} \mathrm{C}$ in a furnace (Daihan Scientific Co., Seoul, Republic of Korea). A voucher specimen (accession number DSSC-1) was deposited at the Medical Research Center for Globalization of Herbal Formulation of Daegu Haany University. The dried seeds were then pulverized and lyophilized in a programmable freeze dryer (Freezone 1; Labconco Co., Kansas City, MO, USA). Lyophilized materials were extracted with $100 \%$ ethanol by maceration at room temperature for $24 \mathrm{~h}$, filtered, and then concentrated using a rotary vacuum evaporator (Buchi Rotavapor R-144, BÜCHI Labortechnik, Flawil, Switzerland). Finally, the SSeo (Lot. 2012KuSSeo) was isolated by hydrodistillation using a Clevenger-type apparatus for $3 \mathrm{~h}$ according to the method recommended in a previous study [40]. The oil was stored in a refrigerator at $4{ }^{\circ} \mathrm{C}$ to protect from light and degeneration. The yield of the oil based on the dried weight of the Schisandrae Semen was $0.66 \%$.

\section{Cell culture}

HASMCs originating from normal human tissue were obtained from Bio-Whittaker (Walkersville, MD, USA). They were cultured in SMC growth medium-2 (Gibco-BRL, Grand Island, NY, USA) containing 10\% fetal bovine serum (FBS), $2 \mathrm{ng} / \mathrm{ml}$ human basic fibroblast growth factor, $0.5 \mathrm{ng} / \mathrm{ml}$ human epidermal growth factor, $50 \mu \mathrm{g} / \mathrm{ml}$ gentamicin, $50 \mu \mathrm{g} / \mathrm{ml}$ amphotericin- $\mathrm{B}$, and $5 \mu \mathrm{g} / \mathrm{ml}$ bovine insulin at $37^{\circ} \mathrm{C}$, in a humidified atmosphere of $5 \% \mathrm{CO}_{2}$ and $95 \%$ air. All experiments were performed with HASMCs from passages 7-13.

\section{Cell viability assay}

The cytotoxic effect of SSeo and TNF- $\alpha$ on HASMCs was investigated using the 3-(4,5-dimethylthiazol-2-yl)2,5-diphenyl tetrazolium bromide (MTT) assay. Briefly, the cells were plated at $5 \times 10^{3}$ cells/well in 96-well culture plates and allowed to attach for $24 \mathrm{~h}$. The cells were either treated or not treated with different concentrations of SSeo for $1 \mathrm{~h}$, and then $100 \mathrm{ng} / \mathrm{mL}$ TNF- $\alpha$ was added. After a $24 \mathrm{~h}$ incubation, MTT solution $(0.5 \mathrm{mg} / \mathrm{ml}$, Sigma-Aldrich Chemical Co., St. Louis, MO, USA) was 
added to each well containing conditioned media and incubated for another $3 \mathrm{~h}$ at $37^{\circ} \mathrm{C}$. Then, the medium was removed and dimethyl sulfoxide (DMSO) was added to each well. After shaking, the absorbance of the solubilized blue formazan was measured at $540 \mathrm{~nm}$ with a microplate reader (Dynatech MR-7000; Dynatech Laboratories, Chantilly, VA, USA) and results were expressed as cell viability relative to the untreated control, which were considered $100 \%$ viable.

\section{Gelatin zymography}

The gelatinolytic activities of MMP-2 and MMP-9 in the conditioning culture medium were assayed by electrophoresis on $10 \%$ polyacrylamide gels containing $1 \mathrm{mg} / \mathrm{mL}$ gelatin at $4^{\circ} \mathrm{C}$. After electrophoresis, the gels were washed in $2.5 \%$ Triton $\mathrm{X}-100$ for $1 \mathrm{~h}$ and incubated at $37^{\circ} \mathrm{C}$ for $24 \mathrm{~h}$ in activation buffer $(50 \mathrm{mM}$ Tris $-\mathrm{HCl}, \mathrm{pH} 7.5$, $150 \mathrm{mM} \mathrm{NaCl}, 10 \mathrm{mM} \mathrm{CaCl}_{2}$, and $\left.0.02 \% \mathrm{NaN}_{3}\right)$. After staining with Coomassie Blue R-250 (10\% glacial acetic acid, 30\% methanol, and 1.5\% Coomassie Brilliant Blue; Invitrogen Co., Carlsbad, CA, USA) for $2 \mathrm{~h}$, the gels were destained with a solution of $10 \%$ glacial acetic acid and $30 \%$ methanol without Coomassie Blue for $1 \mathrm{~h}$. White lysis zones, indicating gelatin degradation, were revealed by staining with Coomassie Brilliant Blue R-250 [41].

\section{In vitro MMP activity assay}

MMP activity in the supernatant was also measured using the MMP Gelatinase Activity Assay Kit (Chemicon International Inc., Temecula, CA, USA), according to the manufacturer's instructions. Briefly, aliquots of culture media were incubated with biotinylated gelatinase substrates provided by the manufacturer to cleave active MMP-2 and MMP-9 in the culture media. The fragments were then added to a biotin-binding 96-well plate and incubated for $30 \mathrm{~min}$ at $37^{\circ} \mathrm{C}$ to allow the biotin-containing fragments to bind to the plate while digestion continued. The digested but unbound fragments were removed by repeated washing, whereas the undigested biotin-labeled gelatinase that bound to the plate was detected by adding a streptavidin-enzyme complex that resulted in a colored product measured at a wavelength of $540 \mathrm{~nm}$ with a microplate reader.

RNA isolation and reverse transcriptase-polymerase chain reaction (RT-PCR)

Total RNA was isolated using TRIzol reagent (Invitrogen Co.) according to the manufacturer's protocol, and $2 \mu \mathrm{g}$ of RNA was used for cDNA synthesis using M-MLV reverse transcriptase (Promega, Madison, WI, USA). RT-generated cDNA encoding MMP-2, MMP-9, tissue inhibitors of metalloproteinase (TIMP)-1, TIMP-2, inducible nitric oxide synthase (iNOS) and cyclooxygenase-2 (COX-2) genes was amplified by PCR using specific primers, which were purchased from Bioneer (Seoul, Republic of Korea).
The PCR primers were as follows: MMP-9 (5' -CGG AGC ACG GAG ACG GGT AT-3' and 5'-TGA AGG GGA AGA CGC ACA GC-3'), MMP-2 (5'-CCC CTA TCT ACA CCT ACA CCA AGA AC-3' and 5'-CCC CTA TCT ACA CCT ACA CCA AGA AC-3'), TIMP-1 (5'-CTG TTG TTG CTG TGG CTG ATA-3' and 5'-CCG TCC ACA AGC AAT GAG T-3'), TIMP-2 (5' -GTA GTG ATC AGG GCC AAA G-3' and 5'-TTC TCT GTG ACC CAG TCC AT-3'), iNOS (5'-ATG GCT TGC CCC TGG AAG TTT CTC-3' and 5'-CCT CTG ATG GTG CCA TCG GGC ATC TG-3'), and COX-2 (5'-TTC ACC AGA CAG ATT GCT GGC-3' and 5' -AGT CTG GAG TGG GAG GCA CTT G-3'). After amplification, the PCR reactants were electrophoresed in $1 \%$ agarose gels and visualized with ethidium bromide (EtBr, Sigma-Aldrich) staining. In a parallel experiment, glyceraldehyde-3-phosphate dehydrogenase (GAPDH, 5'-GAC CTG ACC TGC CGT CTA-3' and 5'-AGG AGT GGG TGT CGC TGT-3') was used as an internal control.

\section{Protein extraction, electrophoresis, and western blot analysis}

Whole-cell protein extracts from HASMCs were prepared with cell lysis buffer $(20 \mathrm{mM}$ sucrose, $1 \mathrm{mM}$ EDTA, $20 \mu \mathrm{M}$ Tris- $\mathrm{HCl}, \mathrm{pH}$ 7.2, $1 \mathrm{mM}$ DTT, $10 \mathrm{mM} \mathrm{KCl}$, $1.5 \mathrm{mM} \mathrm{MgCl}$, and $5 \mu \mathrm{g} / \mathrm{ml}$ aprotinin) for $30 \mathrm{~min}$. The protein extracts were quantified using the Bio-Rad kit (Pierce Biotechnology, Rockford, IL, USA). For Western blot analysis, lysate proteins were resolved on sodium dodecyl sulfate (SDS)-polyacrylamide gel electrophoresis and transferred onto nitrocellulose transfer membranes (Schleicher \& Schuell, Keene, NH, USA). Specific proteins were detected with an enhanced chemiluminescence (ECL) kit (Amersham Co., Arlington Heights, IL, USA) according to the recommended procedure. In a parallel experiment, cells were washed with ice-cold phosphate-buffered saline (PBS) and collected. Then cytoplasmic and nuclear proteins were prepared using NE-PER Nuclear and Cytoplasmic Extraction Reagents (Pierce Biotechnology). Antibodies against MMP-2, MMP-9, TIMP-1, TIMP-2, iNOS, COX-2, $\mathrm{NF}-\kappa \mathrm{B}$ p65, IкB $\alpha$, nucleolin, and actin were purchased from Santa Cruz Biotechnology (Santa Cruz, CA, USA). The peroxidase-labeled donkey anti-rabbit immunoglobulin and peroxidase-labeled sheep anti-mouse immunoglobulin were purchased from Amersham Co.

\section{Immunofluorescence staining}

HASMCs were cultured directly on glass coverslips in 6-well plates for $24 \mathrm{~h}$ to detect NF- $\mathrm{B}$ p 65 localization by immunofluorescence assay using a fluorescence microscope. After stimulation with TNF- $\alpha$ in the presence or absence of SSeo, the cells were fixed with $4 \%$ paraformaldehyde in PBS for $10 \mathrm{~min}$ at room temperature and permeabilized with $100 \%$ methanol for $10 \mathrm{~min}$ at $20^{\circ} \mathrm{C}$. 
Polyclonal antibody against anti-NF- $\mathrm{kB}$ p65 was applied for $1 \mathrm{~h}$ followed by a $1 \mathrm{~h}$ incubation with fluorescein isothiocyanate (FITC)-conjugated donkey anti-rabbit IgG (Santa Cruz Biotechnology). After washing with PBS, nuclei were stained with 4,6-diamidino-2-phenyllindile (DAPI, Sigma-Aldrich) and fluorescence was visualized using a fluorescence microscope (Carl Zeiss, Oberkochen, Germany).

\section{Measurement of ROS generation}

Intracellular accumulation of ROS was determined using the fluorescent probes 2',7'-dichlorodihydrofluorescein diacetate (H2DCFDA, Sigma-Aldrich). Briefly, HASMCs were pretreated with $10 \mathrm{mM}$ nacetylcysteine (NAC), ROS scavenger, or SSeo for $30 \mathrm{~min}$ before treatment with TNF- $\alpha(100 \mathrm{ng} / \mathrm{ml})$ for $30 \mathrm{~min}$. To measure intracellular ROS, the cells were incubated for $4 \mathrm{~h}$ at $37^{\circ} \mathrm{C}$ in PBS containing $20 \mathrm{mM}$ H2DCFDA to label intracellular ROS. ROS production in the cells was monitored with a flow cytometer (FACS Calibur; Becton Dickinson, San Jose, CA, USA) using the Cell-Quest pro software [42].

\section{Nitrite measurement}

Concentrations of nitric oxide (NO) in the culture supernatants were determined by measuring nitrite, a stable oxidation product of NO, using Griess reagent (Sigma-Aldrich). Briefly, the supernatant from cell cultures was collected, mixed with an equal volume of Griess reagent, and incubated at room temperature for 10 min. $\mathrm{NaNO}_{2}$ was used to generate a standard curve, and nitrite production was determined by measuring optical density at $550 \mathrm{~nm}$ [43].

\section{Determination of prostaglandin $\mathrm{E}_{2}\left(\mathrm{PGE}_{2}\right)$ production}

To determine the levels of $\mathrm{PGE}_{2}$, an aliquot of culture medium supernatant was collected and the concentration $(\mathrm{pg} / \mathrm{ml})$ of $\mathrm{PGE}_{2}$ in the cell culture medium was calculated by based on the concentrations of the standard solution using a $\mathrm{PGE}_{2}$ enzyme-linked immunosorbent assay (ELISA) kit following the manufacturer's instructions (Cayman Chemical Co., Ann Arbor, MI, USA).

\section{Cell invasion assay}

The cell migration assay was performed using the Transwell system (Corning Costar, Cambridge, MA, USA). Briefly, HASMCs were resuspended in $100 \mu \mathrm{L}$ of medium and placed in the upper part of the Transwell plate. The cells were incubated for $8 \mathrm{~h}$, fixed with methanol, and then stained with haematoxylin for $10 \mathrm{~min}$ followed by eosin Y (Sigma-Aldrich). HASMCs on the upper surface of the filter were mechanically removed by wiping with a cotton swab, and the migrated cells were determined by counting the cells (three fields of each triplicate filter) that migrated to the lower side of the filter using an inverted microscope.

\section{Statistical analysis}

Data are expressed as the mean \pm standard deviation (SD) values. One-way analysis of variance (ANOVA) was used for comparisons in the experiments with multiple time points and concentrations. When ANOVA indicated statistical significance, Duncan's multiple range test was used to determine which means were significantly different. A probability value of $\mathrm{p}<0.05$ was used as the criterion for statistical significance.

\section{Results}

SSeo inhibits TNF- $a$-induced MMP-9 activation in HASMCs HASMC migration is one of the most important characteristics in atherosclerotic diseases, and the molecular mechanisms have been extensively studied. Many studies indicate that MMPs may participate in the development of atherosclerosis. Among them, an increase in MMP-9 production could contribute to an invasive HASMC phenotype [6-8]; thus, we investigated the effect of SSeo on TNF- $\alpha$-induced MMP-9 activation. HASMCs were treated with TNF- $\alpha(100 \mathrm{ng} / \mathrm{ml})$ in the presence or absence of various concentrations of SSeo for $24 \mathrm{~h}$. At the end of the incubation, media were collected and assayed for MMP activity using gelatin zymography. As shown in Figure 1A, although, MMP-9 had very weak activity, and MMP-2 had a high secretion level in the control condition media, treatment with TNF- $\alpha$ increased the level of MMP-9 secretion, but had no effect on the level of MMP-2 secretion. However, SSeo significantly diminished TNF- $\alpha$-induced MMP-9 secretion in a concentration-dependent manner. Additionally, s similar result was observed in the MMP-9 matrix degradation activity assay but not MMP-2 using the MMP gelatinase activity assay kit (Figure 1B).

\section{Effect of SSeo on HASMCs viability}

HASMCs were exposed to various concentrations of SSeo for $24 \mathrm{~h}$ with or without TNF- $\alpha$, and cellular toxicity was analyzed using the MTT assay. Treatment of HASMCs with the indicated concentrations of SSeo used to inhibit MMP-9 activation did not cause any significant change in cell viability (Figure 2). These results clearly indicate that inhibiting MMP-9 activation in TNF- $\alpha$-stimulated HASMCs was not due to a cytotoxic action of SSeo.

\section{SSeo reduces TNF-a-induced MMP-9 expression in HASMCs}

After the inhibition activity of SSeo on MMP-9 was confirmed, RT-PCR and Western blot analyses were performed to determine the effects of SSeo on the levels of MMP-9 in TNF- $\alpha$-treated HASMCs. Figure 3 illustrates that SSeo concentration-dependently reduced TNF- $\alpha$-induced MMP-9 expression at both the transcriptional and translational levels, but did not affect MMP-2 


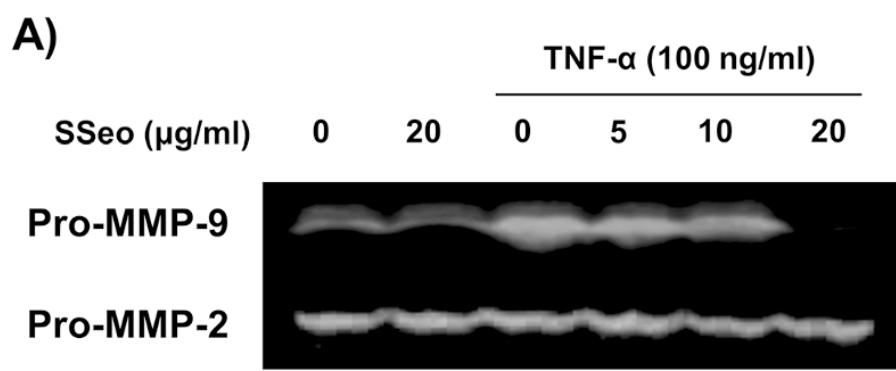

B)

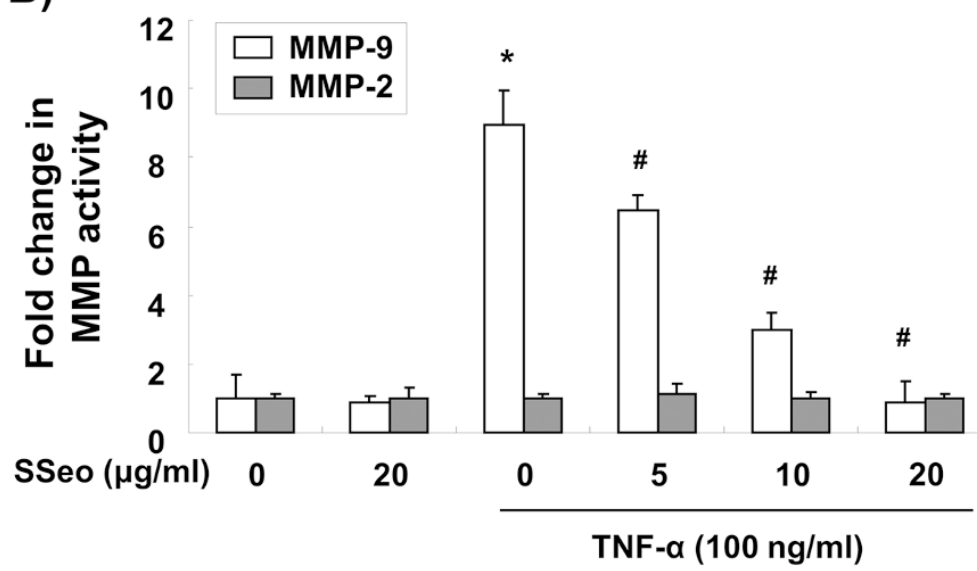

Figure 1 Inhibition of TNF-a-induced MMP-9 activation by SSeo in HASMCs. (A) HASMCs were pretreated for $1 \mathrm{~h}$ with different concentrations of SSeo, followed by incubation with TNF-a for $24 \mathrm{~h}$. The culture medium was collected and analyzed for gelatinolytic activity by zymography. (B) In vitro activity of MMP-2 and -9 in cell culture supernatant was measured using a MMP gelatinase activity assay kit. The biotinylated gelatinase substrates were cleaved by active MMPs in the samples, and the fragments were added to a biotin-binding plate. The digested but unbound fragments were removed by washing. Data are mean \pm SD from three independent experiments and are presented as fold change compared with untreated control cells (*, $p<0.05$ vs. untreated control; ${ }^{*}, p<0.05$ vs. TNF-a-treated HASMCs).

levels. Next, to determine the effects of SSeo on MMPs-related endogenous inhibitors, the levels of TIMP-1 and -2 were examined. As shown in Figure 3, the levels of TIMP-1 and -2 mRNA and protein showed no significant changes in HASMCs treated

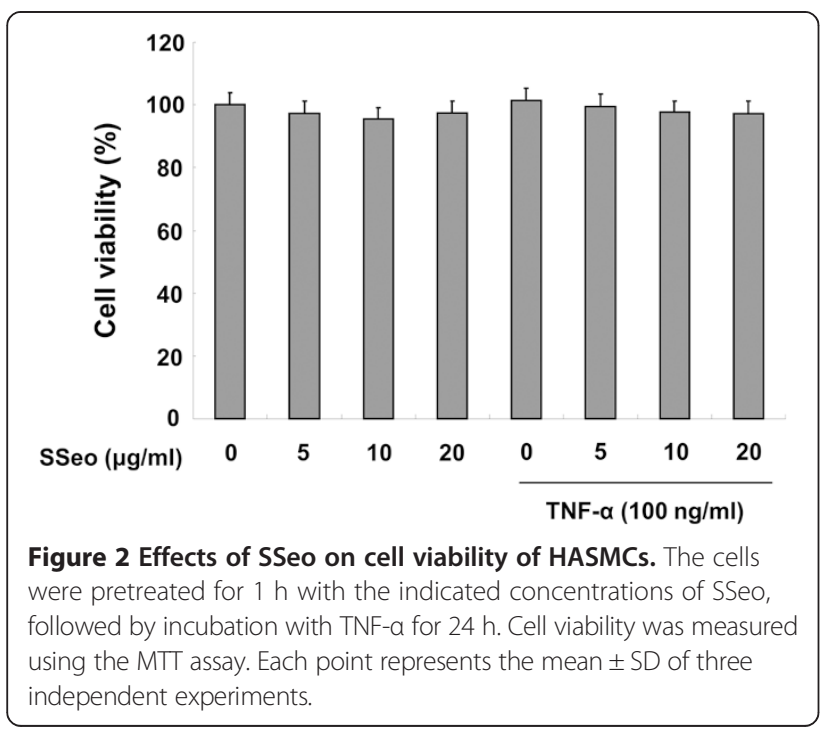

with or without TNF- $\alpha$ and SSeo. These results suggest that SSeo suppresses TNF- $\alpha$-induced MMP-9 activity by inhibiting MMP-9 transcription level in HASMCs, which was not associated with TIMPs expression.

\section{SSeo suppresses TNF-a-induced HASMCs invasion}

As up-regulation of MMP-9 expression by TNF- $\alpha$ contributes to invasion of HASMCs $[7,8]$ and SSeo decreased MMP-9 activity in TNF- $\alpha$ treated HASMCs (Figure 1), an in vitro invasion assay was used to investigate the inhibitory effects of SSeo on the invasive potency of HASMCs by a Matrigel invasion assay. To measure the invasion rate, we counted migrated HASMCs that penetrated the Matrigel and moved to the backside of the Transwell membrane. As shown in Figure 4, treatment with TNF- $\alpha$ significantly increased HASMC invasion, and treatment with SSeo alone partially decreased HASMC invasion compared to that of the control. However, pretreatment with SSeo significantly diminished the TNF- $\alpha$-induced cell invasion to lower levels than those observed in the control, indicating that MMP-9 suppression may play a central role in the 


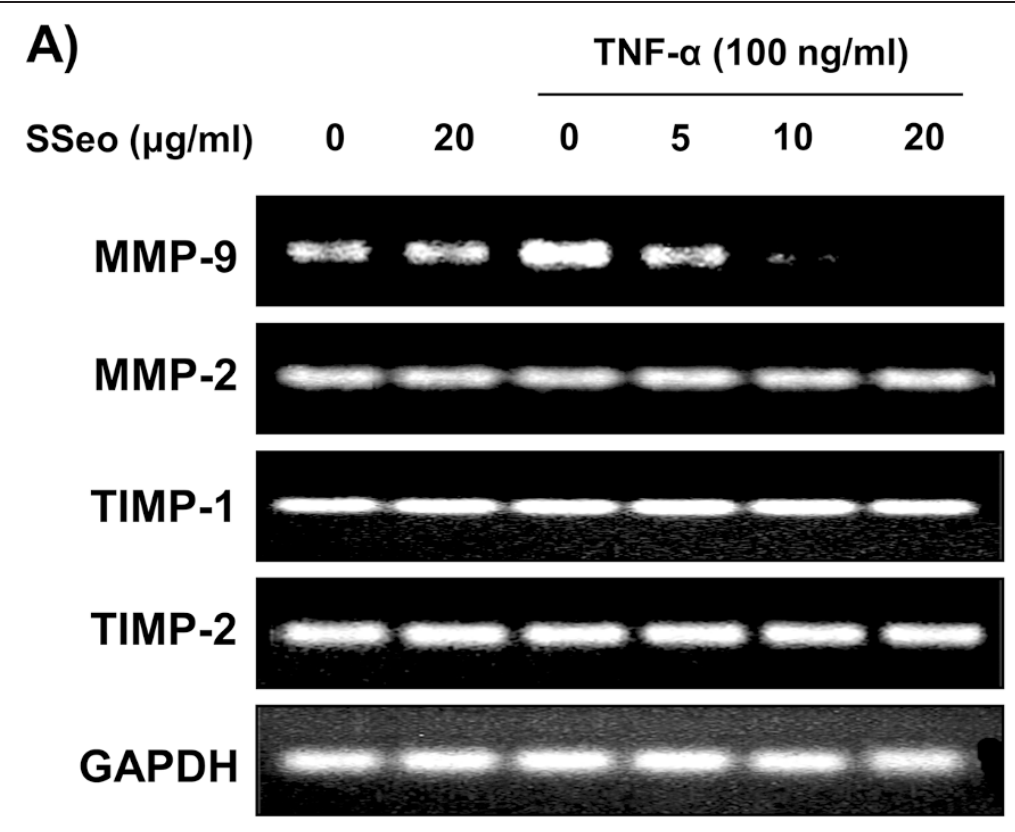

B)

TNF- $\alpha(100 \mathrm{ng} / \mathrm{ml})$

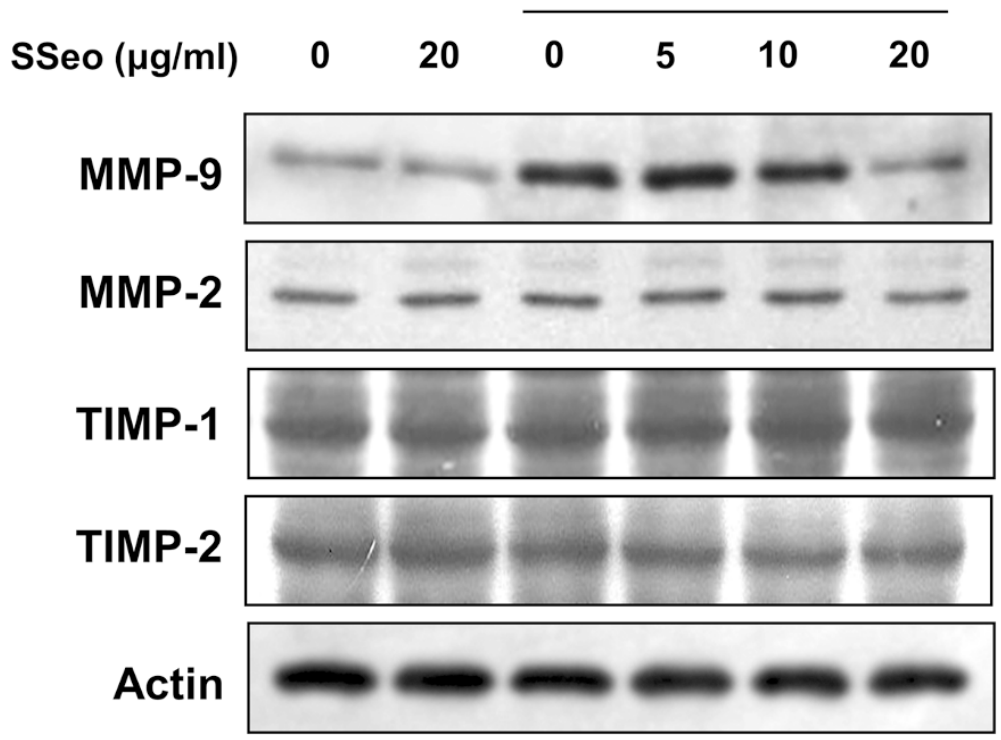

Figure 3 Inhibition of TNF-a-induced MMP-9 mRNA and protein expression by SSeo in HASMCs. (A) Total RNA was isolated from cells grown under the same conditions as Figure 1 and reverse-transcribed. Resulting cDNAs were then subjected to PCR. The reaction products were run on 1\% agarose gel electrophoresis and visualized by EtBr staining. (B) The cells were sampled, lysed, and 30-50 $\mu \mathrm{g}$ of protein was separated by SDS-polyacrylamide gel electrophoresis. Western blotting was then performed using the indicated antibodies and an ECL detection system. GAPDH and actin were used as the internal controls for the RT-PCR and Western blot analyses, respectively.

inhibitory effect of SSeo on TNF- $\alpha$-induced HASMC migration.

SSeo attenuates the TNF-a-induced inflammatory response in HASMCs

Because it is well known that activation of NF- $\mathrm{kB}$ induces the expression of pro-inflammatory mediators [14,15], HASMCs were stimulated with TNF- $\alpha$ for $24 \mathrm{~h}$ in the presence and absence of SSeo to examine the inhibitory effect of SSeo on the TNF- $\alpha$-induced inflammatory response. Treatment of HASMCs with TNF- $\alpha$ alone elevated the levels of pro-inflammatory mediators such as $\mathrm{NO}$ and $\mathrm{PGE}_{2}$ compared to those in the control (Figure 5). However, treating the cells with TNF- $\alpha$ in the presence of SSeo abrogated the ability of TNF- $\alpha$ to induce proinflammatory mediator release. As expected, SSeo also 
A)

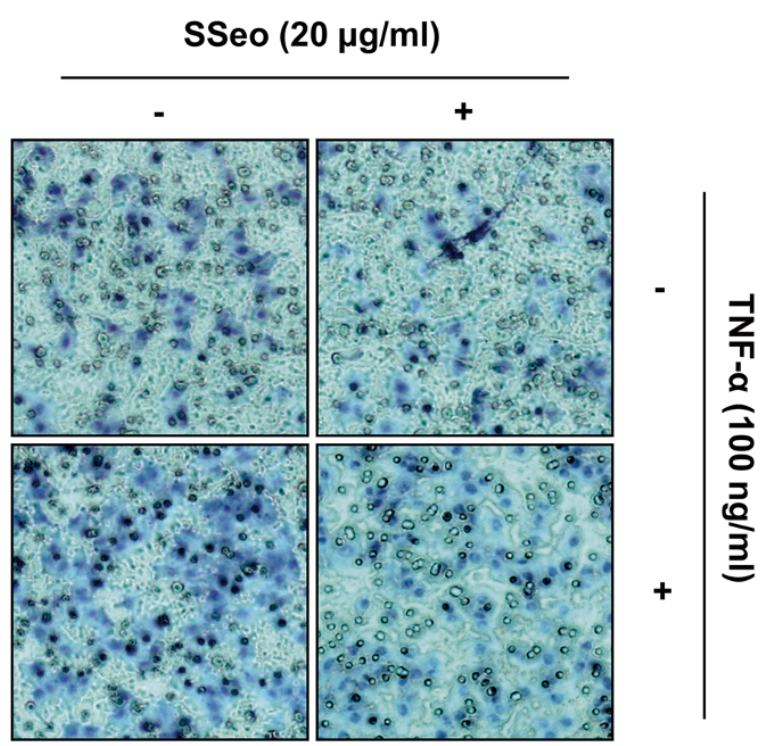

B)

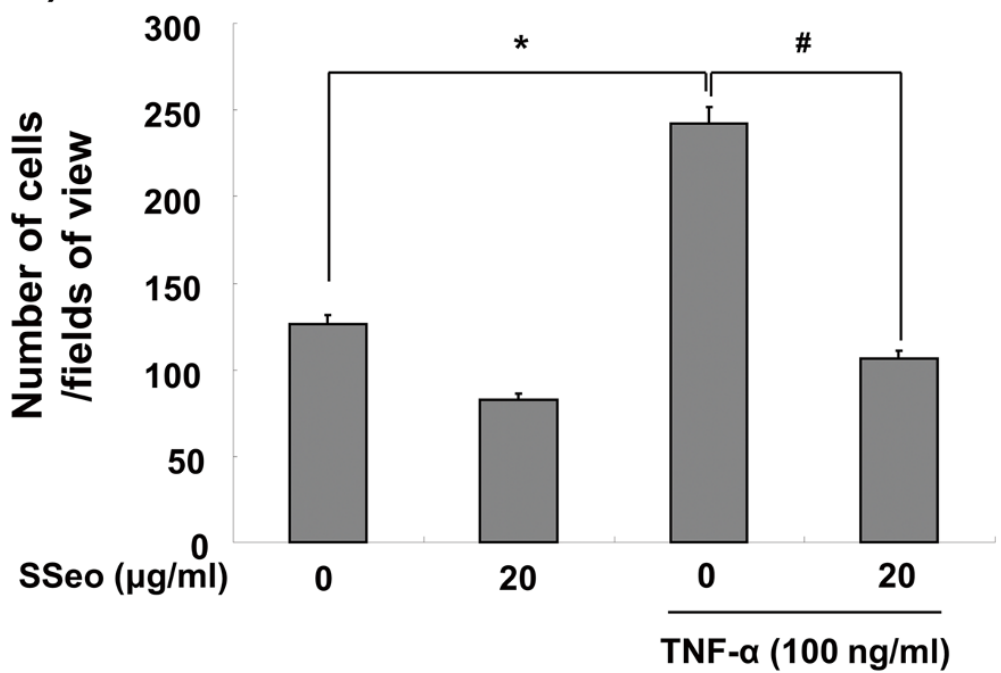

Figure 4 Effects of SSeo on TNF-a-induced HASMC migration. (A) Invasiveness of the cells was determined by measuring their ability to pass through a layer of a Matrigel-coated filter. Following treatment with TNF-a $(100 \mathrm{ng} / \mathrm{ml})$ in the presence or absence of SSeo $(20 \mu \mathrm{g} / \mathrm{ml})$ for $8 \mathrm{~h}$, cells on the bottom side of the filter were fixed, stained and counted. (B) Data from three independent experiments are expressed as overall mean \pm SD. Significance was determined using Student's t-test ( ${ }^{*} p<0.05$ vs. untreated control; ${ }^{*} p<0.05$ vs. TNF-a-treated HASMCs).

attenuated TNF- $\alpha$-induced iNOS and COX-2 mRNA and protein expressions, to levels comparable to those of the control (Figure 6). These results indicate that the reduced expression of pro-inflammatory enzymes at the transcriptional level contributed to the inhibitory effect of SSeo on TNF- $\alpha$-induced $\mathrm{NO}$ and $\mathrm{PGE}_{2}$ production.

\section{SSeo blocks TNF-a-induced ROS formation in HASMCs}

Several studies have reported that TNF- $\alpha$-mediated activation of NF- $\mathrm{KB}$ leads to enhanced ROS production, as a common second messenger, and NF-kB activation, thereby contributing to sustained oxidant production during chronic inflammation $[17,20]$. Therefore, the level of intracellular ROS generation was assessed to determine whether SSeo can reduce the level of TNF- $\alpha$ induced oxidative stress in HASMCs using flow assisted cytometry analysis. As shown in Figure 7, TNF- $\alpha$ significantly enhanced ROS production, while pretreatment with SSeo considerably reversed TNF- $\alpha$-induced cellular ROS production in a concentration-dependent manner, indicating that SSeo is capable of abrogating the increased ROS levels observed in TNF- $\alpha$-treated HASMCs. Treatment with SSeo alone also decreased ROS levels when compared with untreated control cells. 


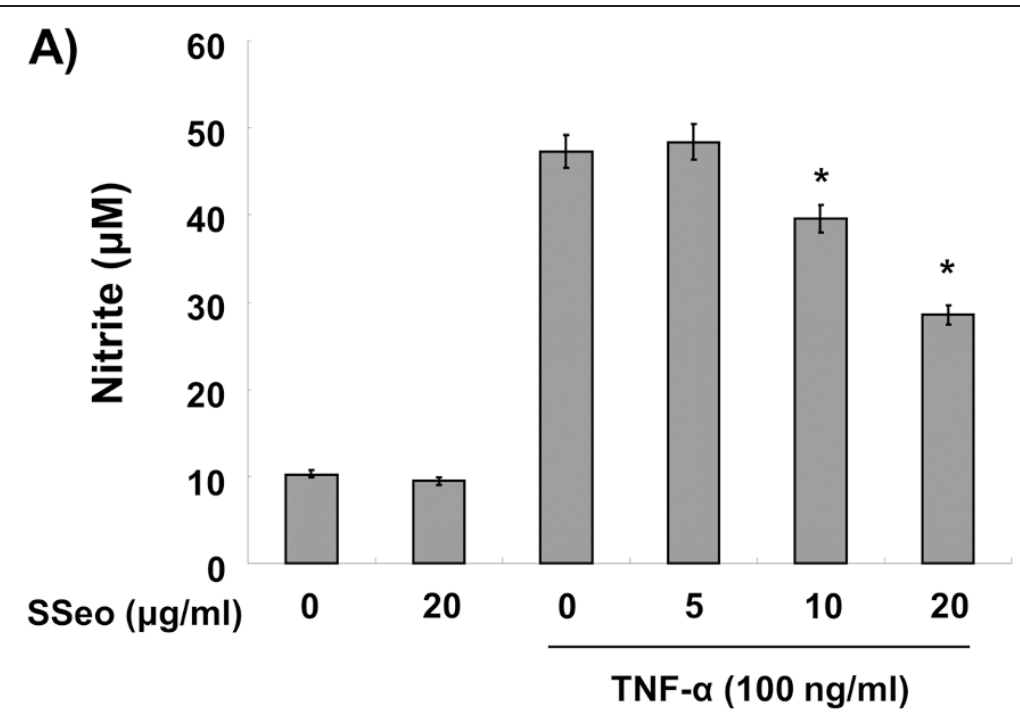

B)

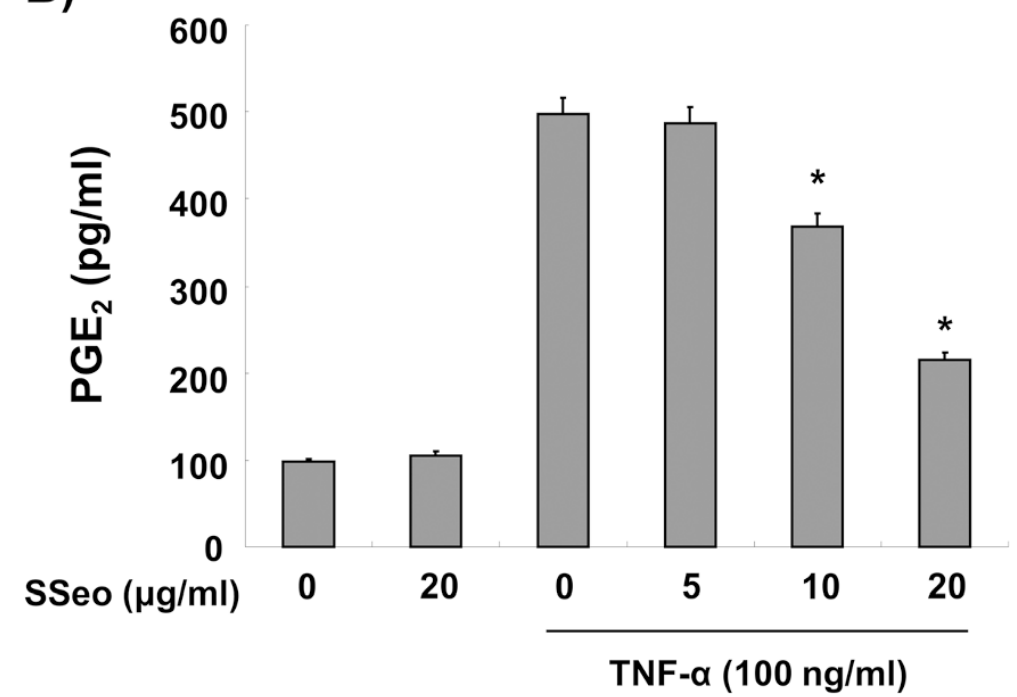

Figure 5 Inhibition of NO and PGE 2 production by SSeo in TNF- $\boldsymbol{a}$-treated HASMCs. HASMCs were pretreated with various concentrations of SSeo for $1 \mathrm{~h}$ before incubation with TNF-a $(100 \mathrm{ng} / \mathrm{ml})$ for $24 \mathrm{~h}$. (A) Nitrite content was measured using the Griess reagent and (B) PGE $\mathrm{C}_{2}$ Concentration was measured in culture media using a commercial ELISA kit. Values represent the mean \pm SD of three independent experiments. We assessed differences between mean values by the Student's $t$-test. ${ }^{*} p<0.05$ indicates significant differences from the TNF-a-treated group.

\section{SSeo inhibits TNF-a-induced nuclear translocation of NF-KB in HASMCs}

Many studies have reported that TNF- $\alpha$-induced NF- $\mathrm{kB}$ activation is involved in upregulating MMP-9 transcriptional activity; thus, we determined whether the inhibitory effect of SSeo on TNF- $\alpha$-induced activation of MMP-9 is mediated through suppression of NF- $\mathrm{B}$ signaling by measuring the nuclear translocation of NF- $\mathrm{kB}$. Western blot analyses using cytosolic and nuclear fractions showed that treatment of TNF- $\alpha$ enhanced nuclear accumulation of NF- $\mathrm{kB}$ proteins, concomitantly with degradation of IкB- $\alpha$ in cytosol. However, pretreatment of HASMCs with SSeo prior to TNF- $\alpha$ stimulation significantly prevented nuclear accumulation of NF-kB, and TNF$\alpha$-induced IкB- $\alpha$ degradation was obviously blocked by pretreatment with SSeo (Figure 8A). The immunofluorescence images also revealed that nuclear accumulation of NF-kB p65 was not induced in cells after treatment with SSeo alone in the absence of TNF- $\alpha$ stimulation; however, that was strongly induced after stimulation of HASMCs with TNF- $\alpha$, and the shift in NF- $\mathrm{kB}$ p65 to the nucleus was completely abolished after pretreating the cells with SSeo (Figure $8 \mathrm{~B}$ ). These results suggest that the inhibitory effect of SSeo on TNF- $\alpha$ induced MMP-9 expression is related to inactivation of NF- $\kappa$ B by preventing I $\mathrm{B}-\alpha$ degradation. 


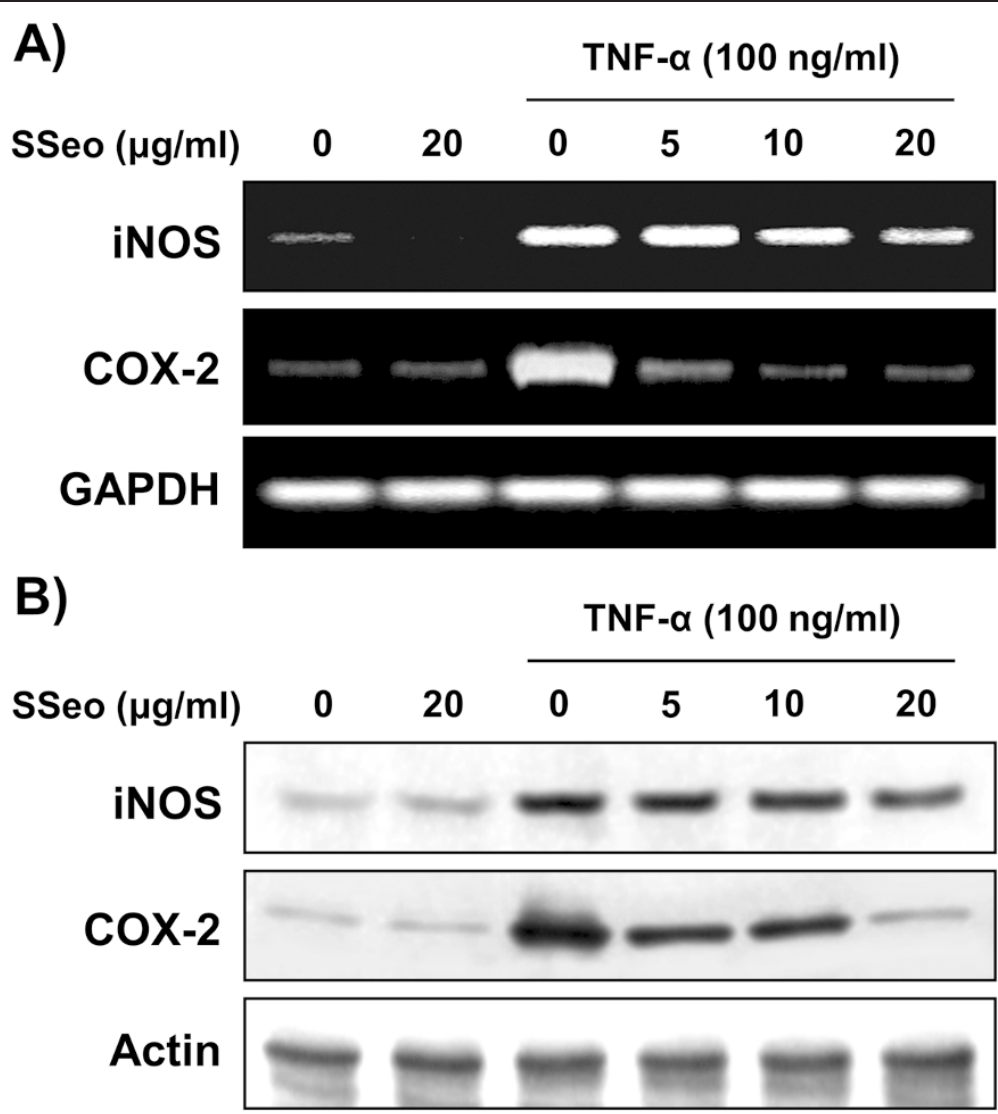

Figure 6 Inhibition of iNOS and COX-2 expression by SSeo in TNF-a-treated HASMCs. (A) HASMCS were pretreated with the indicated concentrations of SSeo $1 \mathrm{~h}$ prior to incubation with TNF-a $(100 \mathrm{ng} / \mathrm{ml})$ for $6 \mathrm{~h}$. Total RNA was prepared for RT-PCR analysis of iNOS and COX-2 gene expression. The reaction products were run on 1\% agarose gel electrophoresis and visualized by EtBr staining. (B) After TNF-a treatment for $24 \mathrm{~h}$, cell lysates were prepared and Western blotting was performed using anti-iNOS and anti-COX-2 antibodies, and an ECL detection system. GAPDH and actin were used as the internal controls of RT-PCR and Western blot analysis, respectively.

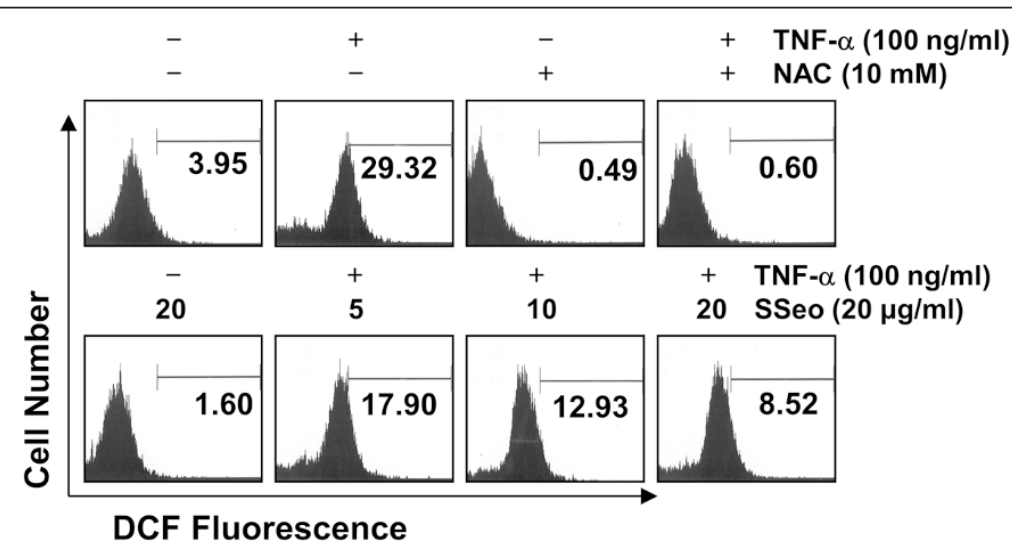

Figure 7 Effects of SSeo on TNF- $a$-induced intracellular ROS generation in HASMCs. HASMCs were treated with NAC (10 mM) or the indicated concentrations of SSeo for 30 min before treatment with TNF-a $(100 \mathrm{ng} / \mathrm{ml})$ for $30 \mathrm{~min}$. The cells were incubated with $20 \mathrm{mM} \mathrm{H2DCFDA}$ at $37^{\circ} \mathrm{C}$ for $30 \mathrm{~min}$, and ROS generation was measured using a flow cytometer. Each point represents the mean of two independent experiments. 

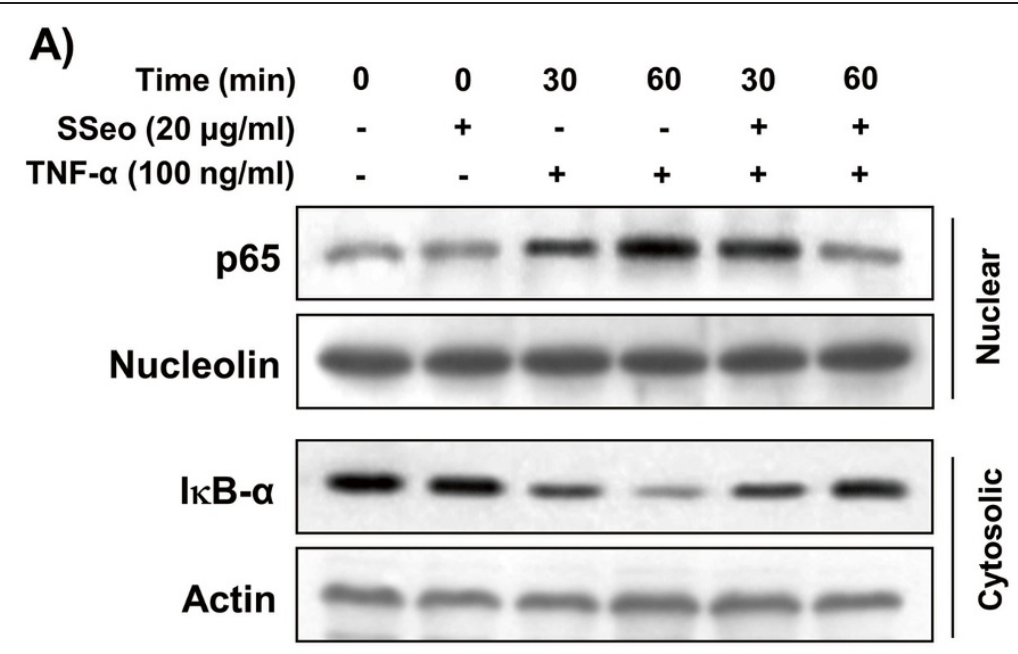

B)

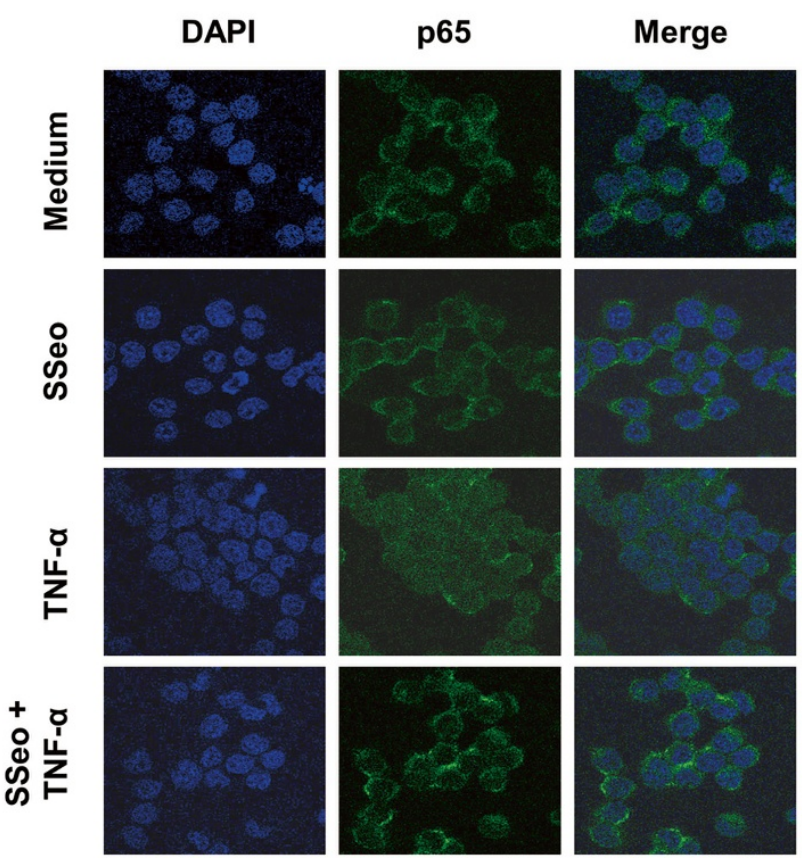

Figure 8 Inhibition of NF-KB nuclear translocation by SSeo in TNF-a-stimulated HASMCs. (A) Cells were pretreated with SSeo (20 $\mu \mathrm{g} / \mathrm{ml})$ for $1 \mathrm{~h}$ before TNF-a treatment (100 ng/ml) for the indicated times. (A) Cytosolic and nuclear proteins were run on 10\% SDS-polyacrylamide gels followed by Western blotting using anti-NF-KB p65 and anti-IKB-a antibodies, and an ECL detection system. Nucleolin and actin were used as internal controls for the nuclear and cytosolic fractions, respectively. (B) The cells were pretreated with SSeo (20 $\mu \mathrm{g} / \mathrm{ml})$ for $1 \mathrm{~h}$ before TNF-a treatment $(100 \mathrm{ng} / \mathrm{ml})$. After a $1 \mathrm{~h}$ incubation, localization of NF-KB p65 was visualized with fluorescence microscopy after immunofluorescence staining with anti-NF-KB p65 antibody (green). Cells were also stained with DAPI to visualize nuclei (blue). Results are representative of those obtained from three independent experiments.

\section{Discussion}

In the present study, we investigated the effects of SSeo on TNF- $\alpha$-induced MMP-9 activation and cell invasion in HASMCs. Our data demonstrate that SSeo effectively inhibited the increased levels of secretion and expression of MMP-9, and the nuclear translocation of the NF- $\mathrm{kB}$ in TNF- $\alpha$-stimulated HASMCs. We also found that SSeo has the ability to suppress the TNF- $\alpha$ - induced release of intracellular ROS and inflammatory mediators such as $\mathrm{NO}$ and $\mathrm{PGE}_{2}$.

A number of studies have demonstrated that the migration of VSMCs from the tunica media to the subendothelial region is a key event in the development and progression of atherosclerosis after vascular injury $[1,2]$. Recent studies have identified enhanced expression of MMPs in atherosclerotic lesions and their contribution 
to weakening of the vascular wall by degrading all kinds of ECM proteins. Among MMPs, MMP-9, which is induced in response to many stimulants, may specifically contribute to the pathogenesis of atherosclerosis by facilitating migration of VSMCs [3,4]. These processes are also promoted by inflammatory mediators and cytokines, as well as cell-cell contact signaling. These observations indicate that the development of therapeutic drugs specifically targeting MMP-9 and inhibition of VSMC migration may be useful for preventing atherosclerotic lesion progression. Our results demonstrated that pretreatment with SSeo significantly inhibited TNF- $\alpha-$ induced MMP-9 secretion by suppressing transcriptional activity of the MMP-9 gene in HASMCs (Figures 1 and 3). In general, the activity of MMPs is tightly controlled by transcriptional activation, by a complex proteolytic activation cascade, and by an endogenous system of TIMPs. TIMPs inhibit MMPs by forming stoichiometric complexes to regulate matrix turnover [44]. However, the transcriptional and translational levels of TIMP-1 and -2 remained unchanged in HASMCs treated with TNF- $\alpha$ alone or in a combined treatment with SSeo at the concentrations tested (Figure 3), suggesting that SSeo suppressed MMP-9 expression by diminishing its gene transcription without abolishing TIMP-1 and -2 expression.

Many studies have identified the signaling mechanisms underlying the regulation of transcription factors that are involved in regulating MMP-9 expression. Most of all, a functional NF- $\mathrm{KB}$ site occurs in the proximal stimulatory region of the MMP-9 promoter $[11,12,15]$, and a previous study demonstrated that transient overexpression of $\mathrm{I}_{\kappa} \mathrm{B} \alpha$ in VSMCs only partially impairs upregulation of MMP-9, suggesting that NF- $\mathrm{kB}$ might play a simple permissive role [45]. Thus, we focused here on defining the role played by the NF- $\mathrm{kB}$ transcription factor in the downregulation of MMP-9 activity by SSeo in TNF- $\alpha$-stimulated HASMCs. In general agreement with previous reports [10-12,14,15], the majority of intracellular NF- $\mathrm{kB}$ p 65 translocated from the cytosol to the nucleus following treatment with TNF- $\alpha$ (Figure 8). However, the levels of NF-kB p65 in the nucleus decreased significantly following pretreatment with SSeo, and TNF- $\alpha$-induced IкB- $\alpha$ degradation was also significantly reversed by SSeo. Furthermore, data obtained from the Matrigel migration assay indicated that SSeo significantly inhibited TNF- $\alpha$-induced migration potential of HASMCs (Figure 4). These results led us to conclude that SSeo inhibits TNF- $\alpha$-induced nuclear translocation of NF- $\mathrm{kB}$, thereby suppressing activation and protein expression of MMP-9, resulting in decreased HASMC migration.

In contrast, oxidative stress is a state in which excess ROS overwhelms endogenous antioxidant systems. Several studies have indicated that ROS are implicated in the activation of NF- $\mathrm{kB}$, and inflammatory mediators are also implicated in the production of ROS. Moreover, previous results indicate that inflammatory mediators, which strongly influence the production of atherosclerotic plaque, stimulate VSMC migration from the intima to the media [16,17]. In addition, oxidative stress affects injured vessels, which develops into inflammation. In contrast, inflammation can also increase ROS on atherosclerotic lesions to regulate cellular reaction such as VSMC proliferation and migration [16,46], suggesting that atherosclerosis is a chronic inflammatory disease associated with increased oxidative stress in the VSMCs. This vicious cycle leads not only to cardiovascular disease but also myocardial infarction, stroke, and heart failure [47]. Thus, reducing oxidative stress and production of inflammatory mediators is important to control atherosclerosis. In our experiments, SSeo pretreatment blocked TNF- $\alpha$-stimulated production of ROS, indicating that SSeo could scavenge radicals (Figure 7). Moreover, SSeo effectively inhibited TNF- $\alpha$-induced NO and $\mathrm{PGE}_{2}$ synthesis (Figure 5) and that this suppression was consistently correlated with downregulation of iNOS and COX-2 expression (Figure 6). Therefore, we propose that the inhibitory effect of SSeo on MMP-9 expression and NF- $\mathrm{KB}$ activation may be due to its antioxidant and anti-inflammatory properties.

\section{Conclusions}

Collectively, our data reveal for the first time that SSeo, an essential oil purified from Schisandrae semen, strongly suppressed TNF- $\alpha$-induced MMP-9 expression and migration of HASMCs by inhibiting activation of the NF-kB signaling pathway. SSeo also effectively downregulated TNF- $\alpha$-induced production of ROS and inflammatory mediators in HASMCs. Although future studies on its regulation of VSMC proliferation and migration in vivo, as well as the detailed mechanisms are needed, these observations indicate that SSeo might be useful as a therapeutic agent for preventing and/or treating vascular disorders related to VSMC migration.

\section{Competing interests}

The authors declare that they have no competing interests.

\section{Authors' contributions}

JWJ, JWK, SKK and GYK have made substantial contributions to conception and design, or acquisition of data, or analysis and interpretation of data. BWK, GYK and YHC have been involved in drafting the manuscript or revising it critically for important intellectual content. SGK, KYK, HJH, CMK and BWK have given final approval of the version to be published; and all of the authors agree to be accountable for all aspects of the work in ensuring that questions related to the accuracy or integrity of any part of the work are appropriately investigated and resolved. All authors read and approved the final manuscript. 


\section{Acknowledgements}

This work was supported by the R\&D program of MOTIE/KIAT (10040391, Development of Functional Food Materials and Device for Prevention of Aging-associated Muscle Function Decrease) and Basic Science Research Program through the National Research Foundation of Korea (NRF) grant funded by the Korea government (No. 2012046358). We thank Aging Tissue Bank for providing research materials.

\section{Author details \\ 'Department of Biochemistry, Dongeui University College of Korean Medicine, Busan 614-052, Republic of Korea. ${ }^{2}$ Research Institute, Bio-Port Korea INC, Marine Bio-industry Development Center, Busan 619-912, Republic of Korea. ${ }^{3}$ Department of Anatomy and Histology, College of Korean Medicine, Daegu Haany University, Gyeongsan 712-715, Republic of Korea. ${ }^{4}$ Laboratory of Immunobiology, Department of Marine Life Sciences, Jeju National University, Jeju 690-756, Republic of Korea. ${ }^{5}$ Anti-Aging Research Center \& Blue-Bio Industry RIC, Dongeui University, Busan 614-714, Republic of Korea. ${ }^{6}$ Department of Food and Nutrition, Dongeui University, Busan 614-714, Republic of Korea. ${ }^{7}$ Department of Life Science and Biotechnology, Dongeui University, Busan 614-714, Republic of Korea. ${ }^{8}$ Molecular Inflammation Research Center for Aging Intervention (MRCA), Department of Pharmacy, Pusan National University, Busan 609-735, Republic of Korea. 'Department of Biochemistry, Busan National University College of Medicine, Yangsan 626-870, Republic of Korea.}

Received: 27 July 2014 Accepted: 14 January 2015 Published online: 05 February 2015

\section{References}

1. Rudijanto A. The role of vascular smooth muscle cells on the pathogenesis of atherosclerosis. Acta Med Indones. 2007;39:86-93.

2. Hopkins PN. Molecular biology of atherosclerosis. Physiol Rev. 2013;93:1317-542

3. Kuzuya M, Iguchi A. Role of matrix metalloproteinases in vascular remodeling. J Atheroscler Thromb. 2003;10:275-82.

4. Newby AC. Matrix metalloproteinase inhibition therapy for vascular diseases. Vascul Pharmacol. 2012:56:232-44

5. Park SH, Koo HJ, Sung YY, Kim HK. The protective effect of Prunella vulgaris ethanol extract against vascular inflammation in TNF-a-stimulated human aortic smooth muscle cells. BMB Rep. 2013;46:352-7.

6. Mason DP, Kenagy RD, Hasenstab D, Bowen-Pope DF, Seifert RA, Coats S, et al. Matrix metalloproteinase-9 overexpression enhances vascular smooth muscle cell migration and alters remodeling in the injured rat carotid artery. Circ Res. 1999:85:1179-85.

7. Estève PO, Chicoine E, Robledo O, Aoudjit F, Descoteaux A, Potworowski EF, et al. Protein kinase $C$-zeta regulates transcription of the matrix metalloproteinase-9 gene induced by IL-1 and TNF-alpha in glioma cells via NF-kappa B. J Biol Chem. 2002;277:35150-5.

8. Sprague AH, Khalil RA. Inflammatory cytokines in vascular dysfunction and vascular disease. Biochem Pharmacol. 2009;78:539-52.

9. Doevendans PA, van Eys G. Smooth muscle cells on the move: the battle for actin. Cardiovasc Res. 2002:54:499-502.

10. Bond M, Chase AJ, Baker AH, Newby AC. Inhibition of transcription factor NF-kappaB reduces matrix metalloproteinase- $1,-3$ and -9 production by vascular smooth muscle cells. Cardiovasc Res. 2001;50:556-65.

11. Knipp BS, Ailawadi G, Ford JW, Peterson DA, Eagleton MJ, Roelofs KJ, et al. Increased MMP-9 expression and activity by aortic smooth muscle cells after nitric oxide synthase inhibition is associated with increased nuclear factorkappaB and activator protein-1 activity. J Surg Res. 2004;116:70-80.

12. Cheng G, Wei L, Xiurong W, Xiangzhen L, Shiguang Z, Songbin F. IL-17 stimulates migration of carotid artery vascular smooth muscle cells in an MMP-9 dependent manner via p38 MAPK and ERK1/2-dependent NF-kappaB and AP-1 activation. Cell Mol Neurobiol. 2009;29:1161-8.

13. Butoi ED, Gan AM, Manduteanu I, Stan D, Calin M, Pirvulescu M, et al. Cross talk between smooth muscle cells and monocytes/activated monocytes via CX3CL1/CX3CR1 axis augments expression of pro-atherogenic molecules. Biochim Biophys Acta. 1813;2011:2026-35.

14. Palanki MS. Inhibitors of AP-1 and NF-kappa B mediated transcriptional activation: therapeutic potential in autoimmune diseases and structural diversity. Curr Med Chem. 2002;9:219-27.
15. Simmonds RE, Foxwell BM. Signalling, inflammation and arthritis: NF-kappaB and its relevance to arthritis and inflammation. Rheumatology (Oxford). 2008;47:584-90.

16. Yung LM, Leung FP, Yao X, Chen ZY, Huang Y. Reactive oxygen species in vascular wall. Cardiovasc Hematol Disord Drug Targets. 2006;6:1-19.

17. Gauss KA, Nelson-Overton LK, Siemsen DW, Gao Y, DeLeo FR, Quinn MT. Role of NF-kappaB in transcriptional regulation of the phagocyte NADPH oxidase by tumor necrosis factor-alpha. J Leukoc Biol. 2007;82:729-41.

18. Sullivan $\mathrm{GW}$, Sarembock IJ, Linden J. The role of inflammation in vascular diseases. J Leukoc Biol. 2000;67:591-602.

19. Touyz RM, Schiffrin EL. Reactive oxygen species in vascular biology: implications in hypertension. Histochem Cell Biol. 2004;122:339-52.

20. Aggarwal S, Gross CM, Sharma S, Fineman JR, Black SM. Reactive oxygen species in pulmonary vascular remodeling. Compr Physiol. 2013;3:1011-34.

21. Siwik DA, Colucci WS. Regulation of matrix metalloproteinases by cytokines and reactive oxygen/nitrogen species in the myocardium. Heart Fail Rev. 2004:9:43-51.

22. González A, Ravassa S, Beaumont J, López B, Díez J. New targets to treat the structural remodeling of the myocardium. J Am Coll Cardiol. 2011;58:1833-43.

23. Oussalah M, Caillet S, Salmiéri S, Saucier L, Lacroix M. Antimicrobial and antioxidant effects of milk protein-based film containing essential oils for the preservation of whole beef muscle. J Agric Food Chem. 2004;52:5598-605.

24. Fratianni F, De Martino L, Melone A, De Feo V, Coppola R, Nazzaro F. Preservation of chicken breast meat treated with thyme and balm essentia oils. J Food Sci. 2010;75:M528-35.

25. Cavanagh HM, Wilkinson JM. Biological activities of lavender essential oil. Phytother Res. 2002;16:301-8.

26. Magalhães PJ, Lahlou S, Santos MA V d, Pradines TL, Leal-Cardoso JH. Myorelaxant effects of the essential oil of Croton nepetaefolius on the contractile activity of the guinea-pig tracheal smooth muscle. Planta Med. 2003;69:874-7

27. Coelho-de-Souza LN, Leal-Cardoso JH, de Abreu Matos FJ, Lahlou S, Magalhães PJ. Relaxant effects of the essential oil of Eucalyptus tereticornis and its main constituent 1,8-cineole on guinea-pig tracheal smooth muscle. Planta Med. 2005;71:1173-5.

28. Koto R, Imamura M, Watanabe C, Obayashi S, Shiraishi M, Sasaki Y, et al. Linalyl acetate as a major ingredient of lavender essential oil relaxes the rabbit vascular smooth muscle through dephosphorylation of myosin light chain. J Cardiovasc Pharmacol. 2006:48:850-6.

29. Evangelista GL, Coelho-de-Souza AN, Santos CF, Leal-Cardoso JH, Lopes EA, dos Santos MV, et al. Essential oil of Pterodon polygalaeflorus inhibits electromechanical coupling on rat isolated trachea. J Ethnopharmacol. 2007;109:515-22

30. Pinho-da-Silva L, Mendes-Maia PV, do Nascimento Garcia TM, Cruz JS, de Morais SM, Coelho-de-Souza AN, et al. Croton sonderianus essential oil samples distinctly affect rat airway smooth muscle. Phytomedicine. 2010;17:721-5.

31. Karim A, Berrabah M, Mekhfi H, Ziyyat A, Legssyer A, Bouali A, et al. Effect of essential oil of Anthemis mauritiana Maire \& Sennen flowers on intestinal smooth muscle contractility. J Smooth Muscle Res. 2010;46:65-75.

32. de Sousa AA, Soares PM, de Almeida AN, Maia AR, de Souza EP, Assreuy AM. Antispasmodic effect of Mentha piperita essential oil on tracheal smooth muscle of rats. J Ethnopharmacol. 2010;130:433-6.

33. Pereira SL, Marques AM, Sudo RT, Kaplan MA, Zapata-Sudo G. Vasodilator activity of the essential oil from aerial parts of Pectis brevipedunculata and its main constituent citral in rat aorta. Molecules. 2013:18:3072-85.

34. Panossian A, Wikman G. Pharmacology of Schisandra chinensis Bail.: an overview of Russian research and uses in medicine. J Ethnopharmacol. 2008;118:183-212.

35. Hancke JL, Burgo RA, Ahumada F. Schisandra chinensis (Turcz.) Baill. Fitoterapia. 1999;70:451-71.

36. Teng $\mathrm{H}$, Lee WY. Antibacterial and antioxidant activities and chemical compositions of volatile oils extracted from Schisandra chinensis Baill. seeds using simultaneous distillation extraction method, and comparison with Soxhlet and microwave-assisted extraction. Biosci Biotechnol Biochem. 2014;78:79-85.

37. Liu CJ, Zhang SQ, Zhang JS, Liang Q, Li DS. Chemical composition and antioxidant activity of essential oil from berries of Schisandra chinensis (Turcz.) Baill. Nat Prod Res. 2012;26:2199-203. 
38. Chen $X$, Zhang $Y, Z u$ Y, Yang L. Chemical composition and antioxidant activity of the essential oil of Schisandra chinensis fruits. Nat Prod Res. 2012;26:842-9.

39. $\mathrm{Ma} \mathrm{CH}$, Yang L, Zu YG, Liu TT. Optimization of conditions of solvent-free microwave extraction and study on antioxidant capacity of essential oil from Schisandra chinensis (Turcz.) Baill. Food Chem. 2012;134:2532-9.

40. Minaiyan M, Ghannadi AR, Afsharipour M, Mahzouni P. Effects of extract and essential oil of Rosmarinus officinalis L. on TNBS-induced colitis in rats. Res Pharm Sci. 2011;6:13-21.

41. Lee YR, Noh EM, Han JH, Kim JM, Hwang BM, Kim BS, et al. Sulforaphane controls TPA-induced MMP-9 expression through the NF-KB signaling pathway, but not AP-1, in MCF-7 breast cancer cells. BMB Rep. 2013;46:201-6.

42. Kim BH, Oh I, Kim JH, Jeon JE, Jeon B, Shin J, et al. Anti-inflammatory activity of compounds isolated from Astragalus sinicus L. in cytokine-induced keratinocytes and skin. Exp Mol Med. 2014;46:e87.

43. Kyung J, Kim D, Park D, Yang YH, Choi EK, Lee SP, et al. Synergistic anti-inflammatory effects of Laminaria japonica fucoidan and Cistanche tubulosa extract. Lab Anim Res. 2012;28:91-7.

44. Lambert E, Dasse E, Haye B, Petitfrere E. TIMPs as multifacial proteins Crit Rev Oncol Hematol. 2004;49:187-98.

45. Bond M, Fabunmi RP, Baker AH, Newby AC. Synergistic upregulation of metalloproteinase- 9 by growth factors and inflammatory cytokines: an absolute requirement for transcription factor NF-kappa B. FEBS Lett. 1998:435:29-34.

46. Madamanchi NR, Moon SK, Hakim ZS, Clark S, Mehrizi A, Patterson C, et al. Differential activation of mitogenic signaling pathways in aortic smooth muscle cells deficient in superoxide dismutase isoforms. Arterioscler Thromb Vasc Biol. 2005;25:950-6

47. Manea A, Simionescu M. Nox enzymes and oxidative stress in atherosclerosis. Front Biosci (Schol Ed). 2012;4:651-70.

\section{Submit your next manuscript to BioMed Central and take full advantage of:}

- Convenient online submission

- Thorough peer review

- No space constraints or color figure charges

- Immediate publication on acceptance

- Inclusion in PubMed, CAS, Scopus and Google Scholar

- Research which is freely available for redistribution 